\title{
Adição de carotenóides naturais e artificiais na alimentação de galinhas poedeiras: efeitos na qualidade de ovos frescos e armazenados
}

\author{
Addition of natural and synthetic carotenoids, in hen feed : effects in the egg quality and storage
}

\author{
Fernanda Papa Spada ${ }^{\mathrm{I}}$ Solange Guidolin Canniatti Brazaca ${ }^{\mathrm{I}}$ Antonio Domingos Coelho $^{\mathrm{II}}$ \\ Vicente José Maria Savino ${ }^{\text {II }}$ Luciano Cristiano França ${ }^{\text {II }}$ Edival Correr ${ }^{\text {II }}$ Edmilson Martins ${ }^{\text {II }}$ \\ Flávia Salgado Fischer ${ }^{\text {III }}$ Dayane Elizabeth Aoqui Lemes ${ }^{\text {III }}$
}

\section{RESUMO}

A pesquisa teve como objetivo avaliar os atributos de qualidade e de durabilidade dos ovos de duas diferentes linhagens de poedeiras, com dietas contendo aditivos artificiais ou naturais, em diferentes períodos de armazenamento. Foram quantificadas durante o armazenamento as variáveis perda de peso, pH da gema e albúmen, gravidade específica, índice de gema (IG) e foi realizada também classificação por peso e Unidade Haugh (UH). Os resultados foram avaliados segundo teste de Tukey $(P \leq 0,05)$. As linhagens diferiram quanto à classificação extra dos ovos, com maior porcentagem para a Isa Brown. Os ovos obtidos das poedeiras Carijó apresentaram maior porcentagem de gema (Carijó 30,66 e Isa-Brown 24,55). O tempo de armazenamento fez com que a porcentagem de gema aumentasse nas duas linhagens (Carijó 30,66 tempo zero para 34,85 depois de 36 dias; e Isa-Brown de 24,55 para 27,48). As dietas com aditivos artificiais ou naturais não influenciaram a porcentagem de clara (\% Clara 58,72 Controle; 59,52 Aditivo; 60,11 Urucum 1,5\%; 59,43 e de gema \%Gema 27,64 Controle; 27,90 Aditivo; 27,21 Urucum $1,5 \% ; 27,66$ Urucum 2\%). O pH da clara diferiu entre os tratamentos no tempo inicial e aos 36 dias de armazenamento, mas o pH da gema não diferiu durante todo o armazenamento. $O$ índice de gema diferiu nos tempos de armazenamento, mas não diferiu considerando os tratamentos. Em dietas com aditivos artificiais ou naturais, as linhagens e os tempos de armazenamento influenciam na qualidade e durabilidade dos ovos.

Palavras-chave: aditivos, natural, artificial, qualidade, Isa Brown, Carijó Barbada.

\section{ABSTRACT}

The research has the aim of evaluating quality and durability attributes of eggs from two hens lines feed with and without natural or synthetics additives, at several storage periods. During storage, weight lost, albumen and yolk $\mathrm{pH}$, specific gravity andyolk index (IG) were quantified, as well as, weight classification and Haugh Unit (HU) The results were analyzed by Tukey test $(P \leq 0.05)$. Quality differences are bigger by lines and storage time and the extra classification of eggs were higher for Isa Brown. The egg of Carijó hens presented more yolk percentage (Carijó 30.66 e Isa-Brown 24.55). The storage higher increased yolk percentage (Carijó 30.66 time zero for 34.85 after 36 days; and Isa-Brown 24.55 for 27.48). Two lines diets with natural or synthetics additives didn't influence the white and yolk percentage (\%white 58.72 Control; 59.52 Aditive; 60.11 Urucum 1.5\%; 59.43 e de yolk and 27.64 Control; 27.90 Aditive; 27.21 Urucum 1.5\%; 27.66 Urucum $2 \%)$. Clear $\mathrm{pH}$ differs among treatments at initial time and at 36 days of storage, but the yolk $\mathrm{pH}$ didn't chage during all storage. The yolk index differed in the storage time, but not at treatments. So, it's possible to concluded that diets with natural and synthetics additives, lines and storage times had influenced quality and durability attributes in the eggs.

Key words: additive, natural, synthetics, quality, Isa Brown, Carijó Barbada.

\section{INTRODUÇÃO}

O melhoramento genético para desempenho das poedeiras se adequa às necessidades do mercado de ovos (TRINDADE et al., 2007). Há preferência dos consumidores por ovos de gema com cor mais amarela/ laranja (MANO, 2007), o que faz com que haja o emprego de corantes artificiais e/ou naturais (HARDER, 2007; PASCHOALIN et al., 2007).

'Departamento de Agroindustria Alimentos e Nutrição, Escola Superior de Agricultura “Luiz de Queiroz” (ESALQ), Universidade de São Paulo (USP), 13418-900, Piracicaba, SP, Brasil. Email: sgcbraza@usp.br. *Autor para correspodência.

IIDepartamento de Genética, ESALQ, USP, Piracicaba, SP, Brasil.

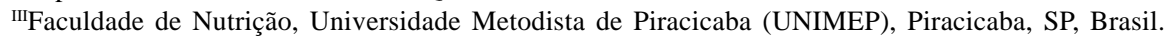


Faz-se necessário então estabelecer critérios para análise da qualidade dos ovos, que variam de acordo com cada país. Para os produtores, a qualidade está ligada ao peso do ovo e resistência da casca; para os consumidores, ao prazo de validade do produto e a características sensoriais (cor da gema e casca) e, para a indústria, está associada à facilidade de retirar a casca, separação da gema e clara, propriedades funcionais e cor da gema (TRINDADE et al., 2007).

As condições de estocagem de ovos, tempo, umidade relativa e temperatura, têm importância na manutenção da qualidade (SANTOS, 2005). A qualidade da casca pode ser avaliada através da gravidade específica (HAMILTON, 1982). Em ovos frescos a qualidade dos componentes internos pode ser avaliada pela Unidade Haugh (ALEONI \& ANTUNUES, 2001) e utilizando o índice de gema (PEEBLES et al., 2000); como parâmetro de qualidade durante períodos de estocagem destaca-se ainda o pH (JORDÃO FILHO et al., 2006).

Este trabalho teve como objetivo avaliar os atributos de qualidade e de durabilidade dos ovos de duas diferentes linhagens de poedeiras, com dietas contendo aditivos artificiais ou naturais, em diferentes períodos de armazenamento.

\section{MATERIAL E MÉTODOS}

Foram utilizadas 80 poedeiras da linhagem experimental Carijó Barbada e 80 da linhagem comercial Isa-Brown, com idade de 33 semanas, que passaram por período de adaptação de duas semanas, alimentadas com dieta comercial. A composição da dieta comercial utilizada como controle e também nos demais tratamentos que receberam os aditivos foi ração para aves a partir de 18 semanas de idade tendo, como composição básica calcário calcítico, farelo de soja, farelo de trigo, milho integral moído, óleo vegetal, premix mineral e vitamínico, aminoácidos e protenose.

No início da 35ª semana de idade, as aves foram divididas em oito tratamentos com 20 poedeiras cada: (A) Carijó Controle; (B) ISA Controle; (C) Carijó Aditivo; (D) ISA Aditivo; (E) Carijó 1,5\% de urucum moído in-natura; (F) ISA 1,5\% urucum moído in natura; (G) Carijó 2\% urucum moído in-natura e (H) ISA 2\% urucum moído in natura. As galinhas foram alojadas em gaiolas individuais, possuindo acesso à água, sendo alimentadas diariamente com ração comercial, contendo urucum moído (peneira ํㅡㄹ 2) nas concentrações de 1,5 e 2,0\% (HARDER et al., 2007) ou aditivo sintético $(0,001 \%$ de carophyll yellow e 0,006\% de carophyll red). Os tratamentos controle receberam ração comercial e amido de milho como inerte. As aves da linhagem Carijó receberam 160 gramas diárias da dieta e as da linhagem Isa-Brown receberam 120 gramas, devido às diferentes exigências nutricionais das aves.

Os ovos foram coletados logo após o fornecimento da ração, uma vez ao dia, e as coletas

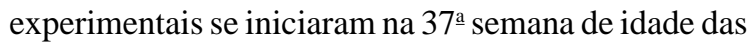
aves. Os ovos submetidos ao armazenamento foram alocados em Câmara Climática 102FC, Eletrolab, em que a temperatura foi controlada a $25^{\circ} \mathrm{C} \pm 0,2$ e a umidade relativa a $90 \%$, durante 14 , 28 e 36 dias.

Para as análises de qualidade física, os ovos foram pesados individualmente em balança digital semianalítica e classificados quanto ao peso segundo legislação vigente (BRASIL, 1965). Obteve-se também o percentual de gema e albúmen, através de diferença, em que primeiro foi pesado o ovo inteiro e posteriormente foram separadas e pesadas cada parte (gema e clara).

Foi utilizado micrômetro $(0,1 \mathrm{~cm})$ para a realização das medidas de altura do albúmen e da gema, para a medida do diâmetro, foi utilizado o paquímetro digital e realizada classificação utilizando-se como base a medida de Unidade Haugh (UH) (USDA, 2000). O pH da clara e da gema foi medido com pHgâmetro digital (MANO, 2007). Foi realizada análise gravimétrica, em ovos frescos, com densímetro (equipamento para medida de densidade) de petróleo para líquidos e concentrações salinas, com densidades entre 1,0650 a 1,0950 (com intervalo de 0,0025).

O delineamento experimental utilizado foi inteiramente ao acaso, com 8 tratamentos (2 linhagens e 4 dietas), e as médias foram comparadas através do teste de Tukey $\left(\mathrm{P}^{\leq} 0,05\right)$ utilizando programa SAS (Statistical Analysis System, 1996).

\section{RESULTADOS E DISCUSSÃO}

A partir do peso dos ovos, foi possível classificá-los conforme a legislação brasileira (Tabela 1), sendo que mais de $40 \%$ dos ovos obtiveram a classificação Extra. Ambas as linhagens e tratamentos contemplam as necessidades dos produtores, obtenção de tamanhos distintos para diferentes faixas de mercado. A adição de carotenóides à dieta não alterou o peso dos ovos.

A linhagem Isa-Brown apresentou peso médio diferente da linhagem Carijó, que é mais pesada. Este resultado está de acordo com SÁ et al. (2007), que encontraram para aves semi-pesadas ovos mais pesados $(62,66 \mathrm{~g})$ que para as aves leves $(60,92 \mathrm{~g})$.

Não houve diferença significativa de densidade entre tratamentos (Figura $1 \mathrm{~A}$ ). Quanto as suas respectivas densidades, foi possível notar que 
Adição de carotenóides naturais e artificiais na alimentação de galinhas poedeiras...

Tabela 1 - Percentual de ovos classificados quanto ao peso segundo Decreto nº 56.585 (BRASIL, 1965).

\begin{tabular}{llccc}
\hline & \multicolumn{5}{c}{ Tratamentos--------------------- } \\
& Extra & Grande & Médio & Pequeno \\
\hline (A) Carijó controle & 52,5 & 32,5 & 15 & 0 \\
(B) ISA controle & 70 & 22,5 & 0 & 7,5 \\
(C) Carijó aditivo & 50 & 37,5 & 7,5 & 5 \\
(D) ISA aditivo & 82,5 & 15 & 2,5 & 0 \\
(E) Carijó 1,5\% & 42,5 & 45 & 10 & 2,5 \\
(F) ISA 1,5\% & 87,5 & 7,5 & 2,5 & 2,5 \\
(G) Carijó 2\% & 57,5 & 40 & 0 & 2,5 \\
(H) ISA 2\% & 72,5 & 25 & 2,5 & 0 \\
-----------------------------Linhagem--------------------------- \\
Carijó & 50,63 & 38,75 & 8,13 & 2,5 \\
Isa- Brown & 78,13 & 17,5 & 1,88 & 2,5 \\
------------------------------Dieta---------------------------- & \\
Controle & 61,25 & 27,5 & 7,5 & 3,75 \\
Aditivo & 66,25 & 26,25 & 5 & 2,5 \\
1,5\% Urucum & 65 & 26,25 & 6,25 & 2,5 \\
2\% Urucum & 65 & 32,5 & 1,25 & 1,25 \\
\hline
\end{tabular}

os ovos frescos possuíam densidade acima de 1,074g $\mathrm{cm}^{-3}$, embora a mensuração tenha se dado a partir de $1,062 \mathrm{~g} \mathrm{~cm}^{-3}$, sendo que a menor densidade que apresentou maior frequência foi de $1,086 \mathrm{~g} \mathrm{~cm}^{-3}$.

Todos os tratamentos tiveram densidades superiores a $1,080 \mathrm{~g} \mathrm{~cm}^{-3}$, ou seja, possuem valores acima dos que são preconizados como normais por BAIÃO \& LÚCIO (2005). Valores maiores de densidade significam maior resistência da casca.

A classificação da UH, segundo o USDA (2000) (Figura 1B), indicou redução da classificação com a estocagem dos ovos classificados nas melhores classes (AA, A e B) e aumento de ovos falhos (fora da classificação). A linhagem Carijó apresentou ovos melhores classificados que a linhagem Isa Brown, já que o número de ovos nas melhores classes foi maior.

Para a perda de peso, não houve diferença significativa após 14 e 36 dias de armazenamento para os oito tratamentos testados. Somente aos 28 dias houve diferença entre o tratamento A e E. Com o aumento dos dias de armazenamento, houve perda de peso, porém, para os tratamentos com adição de urucum ( $\mathrm{G}$ e H), a diferença não foi significativa. O mesmo caso ocorreu para as linhagens no mesmo período e ao longo do tempo (Tabela 2). Não houve diferença significativa entre as dietas no mesmo período. Quando foi comparado o período de armazenamento, as perdas do tratamento com $2 \%$ de urucum não foram significativas.

Para o índice de gema (IG) (Tabela 2), não houve diferença significativa entre os tratamentos e linhagens nos períodos avaliados. Quanto à adição de carotenóides sintéticos na dieta das aves, quando frescos e após 14 dias de armazenamento, estes ovos possuíram melhor IG, contudo essa diferença significativa não ocorreu após 28 e 36 dias de armazenamento.

A comparação entre os períodos demonstrou uma redução do valor do IG, sendo que os tratamentos da linhagem Isa Brown controle, com dietas contendo carotenóides sintéticos e 2\% de urucum, cujos ovos ficaram armazenados por 36 dias não diferiram estatisticamente dos armazenados por 14 dias. Na avaliação separada da linhagem e da dieta, houve diferença entre os períodos, com exceção dos períodos de 28 e 36 dias, fato este que provavelmente está relacionado ao menor número de dias. A dificuldade em mensurar o IG após 36 dias de armazenamento relaciona-se com a fragilidade da membrana vitelínica, que envolve a gema.

Segundo SANTOS (2008), o IG preconizado como ideal está compreendido na faixa de 0,35 a 0,49, entretanto, todos os ovos analisados aos 14 e 28 dias, e a grande maioria dos ovos avaliados após 36 dias de armazenamento, estavam em condições aceitáveis de consumo; portanto, há a possibilidade de considerar como faixa ideal ovos acima de 0,25 para IG.

O IG pode ser recomendado como melhor forma de medida da qualidade do ovo quando comparado a UH e $\mathrm{pH}$, pois esses não mensuram fielmente a qualidade. Com o armazenamento, a UH torna-se falha e o pH apresenta estabilização e/ou pequenas variações não significativas.

A análise dos tratamentos, linhagens e dieta para o percentual de gema (Tabela 3) apresentou diferença estatística entre as linhagens, com maior percentual da linhagem Carijó. Para os tratamentos, linhagem e dieta, houve aumento do percentual de gema com o aumento do período de estocagem, resultado está de acordo com o encontrado por JORDÃO-FILHO et al. (2006). Esse aumento ocorre devido ao acúmulo de água da clara na gema (STADELMAN \& COTTERILL, 1995) e a migração de água da clara para a gema está relacionada às grandes moléculas de proteína que penetram na gema por osmose (BARBOSA et al., 2004).

Observando a tabela 3, foi possível verificar redução no percentual de clara, mesmo para um período reduzido de armazenagem (14 dias); e após 36 dias de armazenamento perda acentuada, como mencionado também por JORDÃO-FILHO et al. (2006) e STADELMAN \& COTTERILL (1995). As menores perdas durante o armazenamento foram apresentadas pela linhagem Isa-Brown, na qual a adição de urucum manteve os mesmos resultados apresentados no 


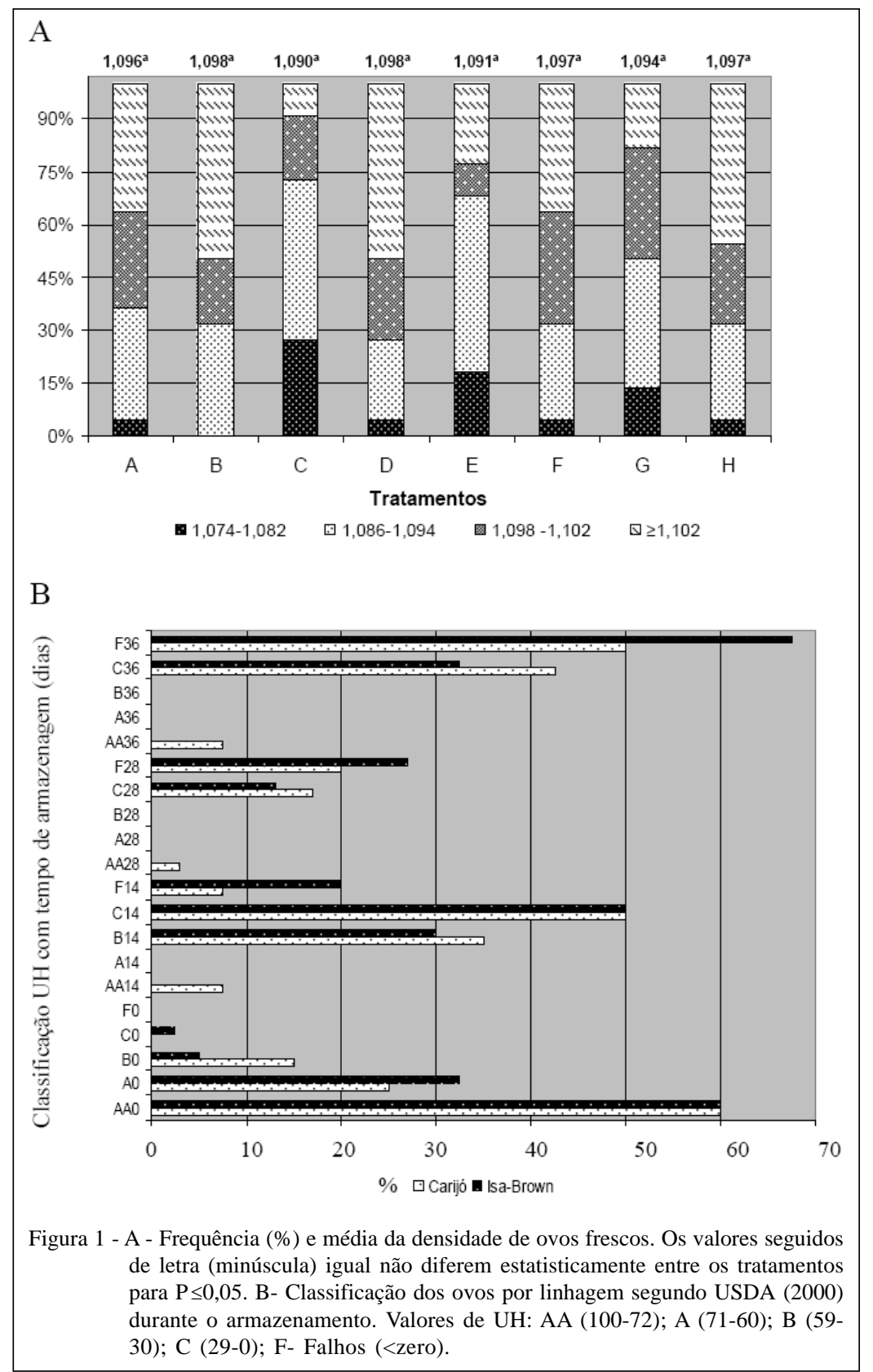

tratamento controle. Desse modo, dentre os aditivos utilizados, o urucum foi o mais eficiente.

Houve diferença significativa para o $\mathrm{pH}$ da clara (Tabela 4) entre o tratamento $\mathrm{H}$ e os tratamentos A, B, C, E e G, quando não houve armazenamento. Entre as linhagens, a diferença existe também quando os ovos estão frescos.

No armazenamento, não houve significância entre os tratamentos dentro do mesmo período para o pH da clara (Tabela 4). Também não houve diferenças com a adição de carotenóides e nem entre linhagens.
Fazendo-se uma avaliação do comportamento do $\mathrm{pH}$ do albúmen ao longo do tempo, houve aumento do $\mathrm{pH}$ após 14 e 28 dias de armazenamento e depois, aos 36 dias, queda em relação aos 14 e 28 dias de armazenamento. Ocorreu exceção do tratamento $F$, que não apresentou alteração significativa de $\mathrm{pH}$ no armazenamento. Para a dieta e as linhagens, ocorreu o mesmo comportamento que para a maior parte dos tratamentos.

Segundo XAVIER et al. (2008), o aumento nos valores de $\mathrm{pH}$ do albúmen ocorre entre os períodos 
Tabela 2 - Médias e desvio padrão de perda de peso e índice gema de ovos frescos e armazenados durante 14, 28 e 36 dias, analisados quanto ao tratamento, a linhagem e a dieta.

\begin{tabular}{|c|c|c|c|c|c|}
\hline & Armazenamento (dias) & Zero & 14 & 28 & 36 \\
\hline \multirow{12}{*}{ 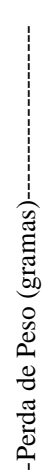 } & \multicolumn{5}{|c|}{ } \\
\hline & (A) Carijó controle & 0 & $1,22 \pm 0,4^{\mathrm{aB}}$ & $0,933 \pm 0,8^{\mathrm{bB}}$ & $1,95 \pm 1,0^{\mathrm{aA}}$ \\
\hline & (B) ISA controle & 0 & $1,01 \pm 0,3^{\mathrm{aB}}$ & $1,22 \pm 0,3^{\mathrm{abB}}$ & $2,14 \pm 1,3^{\mathrm{aA}}$ \\
\hline & (C) Carijó aditivo & 0 & $1,42 \pm 0,5^{\mathrm{aB}}$ & $1,55 \pm 0,3^{a b B}$ & $2,86 \pm 1,9^{\mathrm{aA}}$ \\
\hline & (D) ISA aditivo & 0 & $1,07 \pm 0,3^{\mathrm{aB}}$ & $1,19 \pm 0,7^{\mathrm{abB}}$ & $2,86 \pm 0,4^{\mathrm{aA}}$ \\
\hline & (E) Carijó 1,5\% & 0 & $1,11 \pm 0,2^{\mathrm{aB}}$ & $1,81 \pm 0,5^{\mathrm{aA}}$ & $2,05 \pm 0,8^{\mathrm{aA}}$ \\
\hline & (F) ISA $1,5 \%$ & 0 & $1,34 \pm 0,2^{\mathrm{aB}}$ & $1,05 \pm 0,7^{\mathrm{abB}}$ & $2,68 \pm 1,3^{\text {aA }}$ \\
\hline & (G) Carijó 2\% & 0 & $1,01 \pm 0,8^{\mathrm{aA}}$ & $1,38 \pm 0,7^{\mathrm{abA}}$ & $1,28 \pm 1,7^{\mathrm{aA}}$ \\
\hline & (H) ISA $2 \%$ & 0 & $1,02 \pm 0,7^{\mathrm{aA}}$ & $1,47 \pm 0,6^{\mathrm{abA}}$ & $1,57 \pm 0,8^{\mathrm{aA}}$ \\
\hline & \multicolumn{5}{|c|}{ 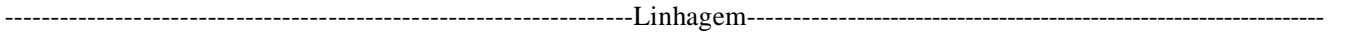 } \\
\hline & Carijó & 0 & $1,18 \pm 0,5^{\mathrm{aB}}$ & $1,41 \pm 0,7^{\mathrm{aB}}$ & $2,04 \pm 1,5^{\mathrm{aA}}$ \\
\hline & Isa- Brown & 0 & $1,11 \pm 0,4^{\mathrm{aB}}$ & $1,23 \pm 0,6^{\mathrm{aB}}$ & $2,07 \pm 1,1^{\mathrm{aA}}$ \\
\hline \multirow{6}{*}{ ! } & Controle & 0 & $1,11 \pm 0,4{ }^{\mathrm{aB}}$ & $1,08 \pm 0,6^{\mathrm{aB}}$ & $2,04 \pm 1,1^{\mathrm{aA}}$ \\
\hline & Aditivo & 0 & $1,24 \pm 0,4^{\mathrm{aB}}$ & $1,36 \pm 0,5^{\mathrm{aB}}$ & $2,38 \pm 1,4^{\mathrm{aA}}$ \\
\hline & $1,5 \%$ Urucum & 0 & $1,22 \pm 0,2^{\mathrm{aB}}$ & $1,43 \pm 0,7^{\mathrm{aB}}$ & $2,36 \pm 1,1^{\mathrm{aA}}$ \\
\hline & 2\% Urucum & 0 & $1,01 \pm 0,7^{\mathrm{aA}}$ & $1,43 \pm 0,7^{\mathrm{aA}}$ & $1,42 \pm 1,3^{\mathrm{aA}}$ \\
\hline & (A) Carijó controle & $0,44 \pm 0,0^{\mathrm{aA}}$ & $0,33 \pm 0,0^{\mathrm{aB}}$ & $0,25^{\mathrm{aC}} \pm 0,0$ & $0,23^{\mathrm{aC}} \pm 0,0$ \\
\hline & (B) ISA controle & $0,44 \pm 0,0^{\mathrm{aA}}$ & $0,31 \pm 0,0^{\mathrm{aB}}$ & $0,26^{\mathrm{aB}} \pm 0,0$ & $0,24 a^{B} \pm 0,0$ \\
\hline \multirow{9}{*}{ 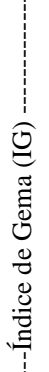 } & (C) Carijó Aditivo & $0,44 \pm 0,0^{\mathrm{aA}}$ & $0,32 \pm 0,0^{\mathrm{aB}}$ & $0,25^{\mathrm{aC}} \pm 0,0$ & $0,25^{\mathrm{aC}} \pm 0,0$ \\
\hline & (D) ISA aditivo & $0,44 \pm 0,0^{\mathrm{aA}}$ & $0,30 \pm 0,0^{\mathrm{aB}}$ & $0,25^{\mathrm{aB}} \pm 0,0$ & $0,26 a^{\mathrm{B}} \pm 0,1$ \\
\hline & (E) Carijó 1,5\% & $0,48 \pm 0,0^{\mathrm{aA}}$ & $0,33 \pm 0,0^{\mathrm{aB}}$ & $0,25^{\mathrm{aC}} \pm 0,0$ & $0,23^{\mathrm{aC}} \pm 0,0$ \\
\hline & (F) ISA $1,5 \%$ & $0,43 \pm 0,0^{\mathrm{aA}}$ & $0,31 \pm 0,0^{\mathrm{aB}}$ & $0,28^{\mathrm{aC}} \pm 0,1$ & $0,23^{\mathrm{aC}} \pm 0,0$ \\
\hline & (G) Carijó 2\% & $0,46 \pm 0,0^{\mathrm{aA}}$ & $0,34 \pm 0,0^{\mathrm{aB}}$ & $0,25^{\mathrm{aC}} \pm 0,0$ & $0,25^{\mathrm{aC}} \pm 0,0$ \\
\hline & (H) ISA 2\% & $0,45 \pm 0,0^{\mathrm{aA}}$ & $0,31 \pm 0,0^{\mathrm{aB}}$ & $0,29^{\mathrm{aB}} \pm 0,0$ & $0,26 \mathrm{a}^{\mathrm{B}} \pm 0,0$ \\
\hline & 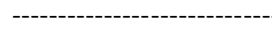 & 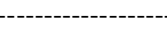 & hagem---- & & \\
\hline & Carijó & $0,45 \pm 0,0^{\mathrm{aA}}$ & $0,33^{\mathrm{abB}} \pm 0,0$ & $0,26 \mathrm{aC} \pm 0,0$ & $0,24^{\mathrm{aC}} \pm 0,0$ \\
\hline & Isa- Brown & $0,44 \pm 0,0^{\mathrm{aA}}$ & $0,31^{\mathrm{bB}} \pm 0,0$ & $0,25 \mathrm{aC} \pm 0,0$ & $0,25^{\mathrm{aC}} \pm 0,0$ \\
\hline \multirow{4}{*}{1} & Controle & $0,44 \pm 0,0^{\mathrm{b}} \mathrm{A}$ & $0,32^{\mathrm{ab}} \mathrm{B} \pm 0,0$ & $0,25^{\mathrm{aC}} \pm 0,0$ & $0,39^{\mathrm{aC}} \pm 0,0$ \\
\hline & Aditivo & $0,47 \pm 0,0^{\mathrm{a}} \mathrm{A}$ & $0,33^{\mathrm{a}} \mathrm{B} \pm 0,0$ & $0,25^{\mathrm{aC}} \pm 0,0$ & $0,24^{\mathrm{aC}} \pm 0,0$ \\
\hline & 1,5\% Urucum & $0,44 \pm 0,0^{\mathrm{ab}} \mathrm{A}$ & $0,31^{\mathrm{ab}} \mathrm{B} \pm 0,0$ & $0,26^{\mathrm{aC}} \pm 0,0$ & $0,25^{\mathrm{aC}} \pm 0,0$ \\
\hline & $2 \%$ Urucum & $0,44 \pm 0,0{ }^{\mathrm{b}} \mathrm{A}$ & $0,30^{\mathrm{b}} \mathrm{B} \pm 0,0$ & $0,26^{\mathrm{aC}} \pm 0,0$ & $0,25^{\mathrm{aC}} \pm 0,0$ \\
\hline
\end{tabular}

Os valores seguidos de letra (minúscula) igual na mesma coluna não diferem estatisticamente entre os tratamentos para $\mathrm{P} \leq 0,05$. Valores seguidos de letras iguais (maiúsculas) na mesma linha não diferem estatisticamente entre os períodos analisados $\mathrm{P} \leq 0,05$.

de zero e 14 dias, em especial nos cinco primeiros dias. O pH passa de 8,35 para 9,45, após 15 dias, considerando a linhagem Hy-line. Para a linhagem Lohman, os valores foram de 7,78 e, após 14 dias a $25^{\circ} \mathrm{C}$, foi de 9,46 (ALEONI \& ANTUNES, 2001).

Segundo MANO (2007), os valores de $\mathrm{pH}$ da clara considerados normais pertencem ao intervalo de 7,5 a 9,7. Todos os ovos analisados demonstraram $\mathrm{pH}$ normais (Tabela 4). Em períodos próximos da postura, o valor encontrado é de pH ácido. Entretanto, os valores de $\mathrm{pH}$ encontrados neste experimento 24 horas após a postura estavam acima de oito (Tabela 4).

Não houve diferença significativa do $\mathrm{pH}$ da gema entre os tratamentos nos períodos de zero, $14 \mathrm{e}$ 28 dias de armazenamento (Tabela 4). Contudo, foi possível notar variações significativas aos 36 dias, quando o tratamento G diferiu de F, E, D e B. Também houve diferença para as linhagens nesse período de armazenamento.

Os ovos cujas aves receberam urucum na dieta possuíam menores valores de $\mathrm{pH}$ da gema, estando mais próximos do preconizado como ideal 
Tabela 3 - Médias e desvio padrão da porcentagem de gema e de clara de ovos frescos e armazenados durante 14, 28 e 36 dias, analisados quanto ao tratamento, a linhagem e a dieta.

\begin{tabular}{|c|c|c|c|c|c|}
\hline & Armazenagem (dias) & 0 & 14 & 28 & 36 \\
\hline \multirow{11}{*}{ 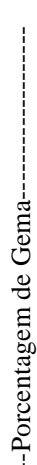 } & \multicolumn{5}{|c|}{----Tratamentos--- } \\
\hline & (A) Carijó controle & $30,24 \pm 2,1 \mathrm{a}^{\mathrm{C}}$ & $32,02 \pm 2,5^{\mathrm{aCB}}$ & $32,89 \pm 1,9$ abAB & $34,88 \pm 2,0$ aA \\
\hline & (B) ISA controle & $25,02 \pm 2,3 b^{B}$ & $24,08 \pm 3,4^{\mathrm{bB}}$ & $26,67 \pm 3,6^{\mathrm{bAB}}$ & $29,24 \pm 2,3^{\mathrm{bA}}$ \\
\hline & (C) Carijó aditivo & $31,18 \pm 1,4 \mathrm{a}^{\mathrm{C}}$ & $32,87 \pm 2,3^{\mathrm{aBC}}$ & $34,62 \pm 3,4^{\mathrm{aAB}}$ & $36,84 \pm 3,4^{\mathrm{aA}}$ \\
\hline & (D) ISA aditivo & $24,62 \pm 1,7 \mathrm{~b}^{\mathrm{A}}$ & $25,51 \pm 3,0^{\mathrm{bA}}$ & $26,66 \pm 2,8^{\mathrm{bA}}$ & $26,94 \pm 2,6^{\mathrm{bA}}$ \\
\hline & (E) Carijó 1,5\% & $30,62 \pm 1,9 a^{A}$ & $32,64 \pm 1,8^{\mathrm{aA}}$ & $31,49 \pm 4,5^{\mathrm{abA}}$ & $33,18 \pm 4,2$ aA \\
\hline & (F) ISA $1,5 \%$ & $23,81 \pm 2,4 b^{C}$ & $24,36 \pm 2,3^{\mathrm{bBC}}$ & $28,47 \pm 4,0^{\mathrm{abA}}$ & $27,92 \pm 2,8^{\mathrm{bAB}}$ \\
\hline & (G) Carijó 2\% & $30,58 \pm 1,8 \mathrm{a}^{\mathrm{C}}$ & $31,99 \pm 1,8{ }^{a B C}$ & $33,29 \pm 2,4^{\mathrm{abAB}}$ & $34,51 \pm 1,5^{\mathrm{aA}}$ \\
\hline & (H) ISA $2 \%$ & $24,74 \pm 1,8 b^{A}$ & $26,20 \pm 2,2^{\mathrm{bA}}$ & $26,83 \pm 3,5^{\mathrm{bA}}$ & $25,82 \pm 2,2^{\mathrm{bA}}$ \\
\hline & Carijó & $30,66 \pm 1,8^{\mathrm{aC}}$ & $32,38 \pm 2,1^{\mathrm{aB}}$ & $33,07 \pm 3,2^{\mathrm{aAB}}$ & $34,85 \pm 3,1^{\mathrm{aA}}$ \\
\hline & Isa- Brown & $24,55 \pm 2,0$ вв & $25,04 \pm 2,8^{\text {ьв }}$ & $27,16 \pm 3,5^{\mathrm{bA}}$ & $27,48 \pm 2,7^{\mathrm{bA}}$ \\
\hline & Controle & $27,64 \pm 3,4^{\mathrm{aB}}$ & $28,05 \pm 5,0$ aB & $29,78 \pm 4,2^{\text {аАВ }}$ & $32,06 \pm 3,6^{\text {aA }}$ \\
\hline & Aditivo & $27,90 \pm 3,7^{\mathrm{aA}}$ & $29,11 \pm 4,6^{\mathrm{aA}}$ & $30,64 \pm 5,1^{\mathrm{aA}}$ & $31,88 \pm 5,8{ }^{\text {aA }}$ \\
\hline i & $1,5 \%$ Urucum & $27,21 \pm 4,1$ aA & $28,50 \pm 4,7^{\text {aA }}$ & $29,98 \pm 5,1^{\mathrm{aA}}$ & $30,55 \pm 4,4^{\mathrm{aA}}$ \\
\hline & $2 \%$ Urucum & $27,66 \pm 3,4^{\mathrm{aA}}$ & $29,10 \pm 3,6^{\mathrm{aA}}$ & $30,06 \pm 4,4^{\mathrm{aA}}$ & $30,17 \pm 4,81^{\mathrm{aA}}$ \\
\hline 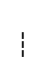 & (A) Carijó controle & $55,67 \pm 5,5^{\mathrm{bA}}$ & $55,53 \pm 2,4$ bсA & $54,19 \pm 1,9^{\mathrm{abA}}$ & $55,51 \pm 5,9$ abcA \\
\hline & (B) ISA controle & $61,77 \pm 3,2^{\mathrm{aA}}$ & $62,11 \pm 4,1^{\mathrm{aA}}$ & $59,51 \pm 4,4^{\mathrm{aAB}}$ & $57,45 \pm 2,1^{\mathrm{abB}}$ \\
\hline & (C) Carijó aditivo & $57,05 \pm 1,6^{\text {bA }}$ & $54,39 \pm 2,7^{\mathrm{cAB}}$ & $50,68 \pm 3,5^{\text {bBC }}$ & $49,98 \pm 5,0^{\mathrm{cC}}$ \\
\hline & (D) ISA aditivo & $61,98 \pm 3,0^{\mathrm{aA}}$ & $60,96 \pm 3,4^{\mathrm{aA}}$ & $59,44 \pm 3,4^{\mathrm{aA}}$ & $59,31 \pm 8,8^{a b A}$ \\
\hline 我 & (E) Carijó 1,5\% & $58,06 \pm 2,5^{a b A}$ & $54,10 \pm 2,3^{\mathrm{cA}}$ & $55,20 \pm 11,1^{a b A}$ & $53,88 \pm 4,7^{\mathrm{abc} A}$ \\
\hline 茪 & (F) ISA $1,5 \%$ & $62,16 \pm 4,4^{\mathrm{aA}}$ & $62,36 \pm 2,5^{\mathrm{aA}}$ & $61,49 \pm 9,3^{\mathrm{abA}}$ & $59,03 \pm 5,2^{\mathrm{abA}}$ \\
\hline ช & (G) Carijó 2\% & $56,99 \pm 1,9^{\mathrm{bA}}$ & $55,43 \pm 2,7^{\text {bcAB }}$ & $54,56 \pm 2,6^{\mathrm{abAB}}$ & $54,41 \pm 1,4{ }^{\text {bcB }}$ \\
\hline 范 & (H) ISA $2 \%$ & $61,86 \pm 1,5^{\mathrm{aA}}$ & $59,29 \pm 4,6^{\mathrm{abA}}$ & $59,17 \pm 5,3^{\text {bA }}$ & $60,14 \pm 2,3^{\mathrm{aA}}$ \\
\hline 菢 & Carijó & $56,94 \pm 3,2^{\mathrm{bA}}$ & $\begin{array}{l}54,86 \pm 2,5^{\mathrm{bAB}} \\
\end{array}$ & $53,65 \pm 6,1$ ьв & $53,08 \pm 4,8^{\mathrm{bB}}$ \\
\hline$\rho_{1}^{0}$ & Isa- Brown & $61,95 \pm 3,1^{\mathrm{aA}}$ & $61,18 \pm 3,8^{\mathrm{aAB}}$ & $59,90 \pm 5,9^{\text {аАв }}$ & $58,98 \pm 5,2^{\mathrm{aB}}$ \\
\hline & Controle & $58,72 \pm 5,4^{\mathrm{aA}}$ & $58,82 \pm 4,7^{\mathrm{aA}}$ & $56,85 \pm 4,3^{\mathrm{aA}}$ & $56,48 \pm 4,4^{\mathrm{aA}}$ \\
\hline & Aditivo & $59,52 \pm 3,4^{\mathrm{aA}}$ & $57,68 \pm 4,5^{\text {аАв }}$ & $55,06 \pm 5,6^{\mathrm{aAB}}$ & $54,64 \pm 8,5^{\mathrm{aB}}$ \\
\hline 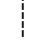 & 1,5\% Urucum & $60,11 \pm 4,1^{\mathrm{aA}}$ & $58,23 \pm 4,8^{\text {aA }}$ & $58,34 \pm 10,5^{\mathrm{aA}}$ & $56,45 \pm 5,5^{\text {aA }}$ \\
\hline & $2 \%$ Urucum & $59,43 \pm 3,0^{\mathrm{aA}}$ & $57,36 \pm 4,2^{\mathrm{aA}}$ & $56,86 \pm 4,7^{\mathrm{aA}}$ & $56,55 \pm 4,1^{\mathrm{aA}}$ \\
\hline
\end{tabular}

Os valores seguidos de letra (minúscula) igual na mesma coluna não diferem estatisticamente entre os tratamentos para $\mathrm{P} \leq 0,05$. Valores seguidos de letras iguais (maiúsculas) na mesma linha não diferem estatisticamente entre os períodos analisados $\mathrm{P} \leq 0,05$.

$(\mathrm{pH}=6,00)$; as diferenças significativas apareceram após 28 e 36 dias de armazenamento. A análise de cada linhagem ao longo do tempo mostrou diferenças estatísticas, sendo os valores mais desfavoráveis encontrados no intervalo de 28 dias.

$\mathrm{O}$ pH da gema aumentou significativamente com o armazenamento prolongado, o que parece corroborar a afirmação de SHANG et al. (2004) de que, durante a armazenagem sob refrigeração (28 dias), íons alcalinos, como sódio, potássio e magnésio migram do albúmen para a gema, trocados pelos íons hidrogênio, provocando o aumento do $\mathrm{pH}$ da gema (JORDÃOFILHO et al. 2006).

\section{CONCLUSÃO}

Dentre os aditivos utilizados, o urucum foi o mais eficiente e influenciou positivamente no $\mathrm{pH}$ do albúmen. A adição de carotenóides na dieta não alterou o peso e a densidade dos ovos. Foi possível estabelecer o IG como o melhor indicador de qualidade. $\mathrm{O}$ armazenamento alterou a UH nas condições deste estudo, demonstrando eficiência desta metodologia.

Considerando os valores de IG e UH na condição ambiental testada, o limite de consumo dos ovos é de 28 dias. Os ovos de postura com até 14 dias de armazenamento possuem qualidade elevada. 
Tabela 4 - Médias e desvio padrão de pH da gema e de clara em ovos frescos e armazenados durante 14, 28 e 36 dias, analisados quanto ao tratamento, a linhagem e a dieta.

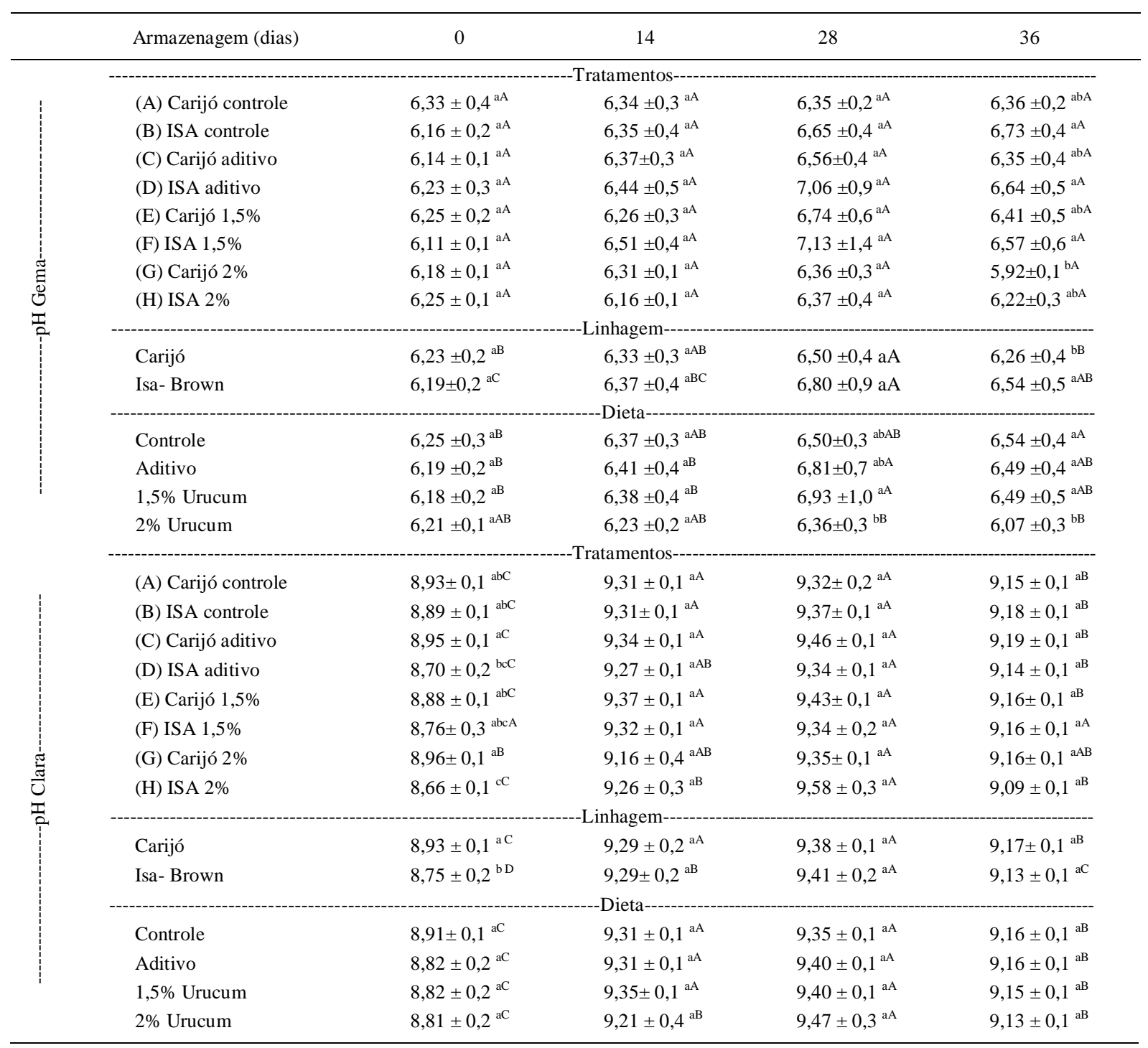

Os valores seguidos de letra (minúscula) igual na mesma coluna não diferem estatisticamente entre os tratamentos para $\mathrm{P} \leq 0,05$. Valores seguidos de letras iguais (maiúsculas) na mesma linha não diferem estatisticamente entre os períodos analisados $\mathrm{P} \leq 0,05$.

Quanto às linhagens, a Carijó Barbada apresentou maior peso dos ovos e percentual de gema. Os ovos da linhagem Isa-Brown, alimentada com dieta de $2 \%$ de urucum, não apresentaram perda de peso significativa quando armazenados.

\section{COMITÊ DE ÉTICA E BIOSSEGURANÇA}

Comitê de Ética para uso de animais em pesquisa do Centro de Energia Nuclear na Agricultura (CEEA-CENA) aprovado em 26/07/2007.

\section{REFERÊNCIAS}

ALLEONI A.C.C; ANTUNES, A.J. Unidade Haugh como medida da qualidade de ovos de galinha armazenados sob refrigeração. Sciencia Agrícola, v.58, n.4, p.681-685, 2001. Disponível em: $<$ http://www.scielo.br/scielo.php?script=sci_arttext\&pid=S010390162001000400005\&lng=pt\&nrm=iso $>$. Acesso em: 16 out. 2011. doi: 10.1590/S0103-90162001000400005.

BAIÃO, N.C.; LÚCIO. C.G. Nutrição de matrizes pesadas. In: MACARI, M.; GONZÁLES, E. Manejo de matrizes de corte. Campinas: Facta, 2005. p.197-216. 
BARBOSA, N.A.A. et al. Efeito da temperatura e do tempo de armazenagem na qualidade interna de ovo de poedeiras comerciais. Revista Brasileira de Ciência Avícola, v.6, suppl.6, p.60, 2004.

BRASIL. Decreto n.56.585, de 20 de julho de 1965. Dispõe sobre especificações para a classificação e fiscalização do ovo. Capturado em: 28 jun. 2007. On line. Disponível em: <http://extranet.agricultura.gov.br/sislegisconsulta/ consultarLegislacao.do?operacao=visualizar\&id=4016>.

JORDÃO FILHO, J. et al. Efeitos da relação metionina + cistina:lisina sobre os desempenhos produtivo e econômico e a qualidade interna e externa dos ovos antes e após 28 dias de armazenamento. Revista Brasileira de Zootecnia, v.35, suppl.4, p.1735-1743, 2006.

HARDER, M.N.C. et al. Cholesterol and iron availability in yolk of laying hens feed with annatto (Bixa orellana). Animal Science, v.1, n.1, p.477-482, 2007

HAMILTON, R.M.G. Methods and factors that affect the measurement of egg shell quality. Poultry Science, v.61. p.2002-2039,1982

MANO, S. Qualidade dos ovos e seus derivados. Avicultura Industrial, v.98, n.6, p.48-52, 2007.

PEEBLES, E.D. et al. Effects of breeder age and dietary fat source and level on broilerhatching egg characteristics. Poultry Science, v.79, p.698-704, 2000.

SÁ, L.M. et al. Exigência nutricional de lisina digestível para galinhas poedeiras no período de 34 a 50 semanas de idade. Revista Brasileira de Zootecnia, v.36, n.6, p.18291836,2007.
SANTOS, M.S.V. Avaliação do desempenho e qualidade dos ovos de poedeiras comerciais, submetidas às dietas suplementadas com diferentes óleos vegetais. 2005. $174 \mathrm{f}$. Tese (Doutorado em Zootecnia) - Universidade Federal do Ceará, Fortaleza, CE.

SANTOS, A.L. Desempenho, crescimento, qualidade do ovo, composição centesimal corporal e características reprodutivas e ósseas de poedeiras submetidas a diferentes programas nutricionais. 2008. 165f. Tese (Doutorado em Zootecnia) - Faculdade de Zootecnia e Engenharia de Alimentos - Universidade de São Paulo, Pirassununga, SP.

SHANG, X.G. et al. Effects of dietary conjugated linoleic acid on the productivity of laying hens and egg quality during refrigerated storage. Poultry Science, v.83, n.10, p.16881695, 2004.

STADELMAN, W.J.; COTTERILL, O.J. Egg science and technology. 4.ed. New York: Food Products, 1995. 591p.

TRINDADE, J.L. et al. Qualidade do ovo de galinhas poedeiras criadas em galpões no semi-árido paraibano. Revista Brasileira de Engenharia Agrícola e Ambiental, v.11, n.6, p.652657, 2007.

USDA. Egg-grading manual. Washington: Department of Agriculture, 2000. 56p. (Agricultural Markenting Service, 75).

XAVIER, I.M.C. et al. Qualidade de ovos de consumo submetidos a diferentes condições de armazenamento. Arquivo Brasileiro Medicina Veterinária e Zootecnia, v.60, n.4, p.953-959, 2008. 